\title{
REABILITAÇÃO DE SOLOS EM ÁREAS MINERADAS: PROCESSOS GEOQUIMIICOS ASSOCIADOS AO DESENVOLVIMENTO DE MACRO E MICRO ESTRUTURAS (EXEMPLO DE POÇOS DE CALDAS, MG)
}

\author{
I.Weissberg ${ }^{1}$ \\ M.C.Toledo-Groke ${ }^{2}$
}

As áreas bauxíticas mineradas em Poços de Caldas (MG), pela ALCOA, estão sofrendo a aplicação de diferentes procedimentos para recomposição do solo superficial, reinstalação da vegetação e reformulação da paisagem, em experimentos de reabilitação do solo.

Observa-se que o plantio de sementes ou mudas em áreas exauridas preparadas com os materiais disponiveis no local, recolocando ou não o top soil retirado e estocado antes da lavra, e aplicando técnicas agronômicas comuns, não é necessariamente eficiente. A eficiência deste plantio depende da existência de condições texturais e estruturais para a circulação das soluções, das características mineralógicas e químicas dos materiais (existência e disponibilidade de nutrientes) bem como de condições climáticas e topográficas favoráveis.

Com o objetivo de investigar as condições mais favoráveis à reabilitação dos solos de áreas mineradas, está sendo efetuado um estudo experimental, com monitoramento, há três anos, de oito sftios em vias de reabilitação,onde foram utilizadas diferentes técnicas de preparo do substrato e de semeadura:

- 2 áreas de solos naturais onde existem dois tipos bem distintos de vegetação (mata subtropical e campo cerrado);

- 3 áreas com 13, 7 e 5 anos de reabilitação, preparadas em bancadas e semeadas com diferentes espécies vegetais (eucalipto, bracaatinga e espécies nativas com forrageiras,

\footnotetext{
1Pós-graduação, Departamento de Geologia Geral, Instituto de Geociências, USP.

${ }^{2}$ Departamento de Geologia Geral, Instituto de Geociências e Núcleo de Pesquisa em Geoquímica e Geofísica da Litosfera, USP.
} 
respectivamente) nas superfícies horizontais;

- 2 áreas com 4 e 2 anos de reabilitação, também preparadas em bancadas, mas onde o material disponível após a lavra sofreu preparo agronômico com corretivo de solos, fertilizantes e uso de gradeamento e arado;

- uma área com 2 anos de reabilitação, cuja superfície foi suavizada e onde foi aplicado o "top soil" anteriormente armazenado. Além disso, foi utilizado um implemento agrícola especial para sulcar a terra (riple), com aplicação de corretivos e fertilizantes. Este sítio foi dividido em três zonas, que receberam semeadura, respectivamente, de plantas nativas, capim barba de bode e capim gordura e, finalmente, plantas nativas e serapilheira retirada de área adjacente.

Entre estas zonas foram reservadas três áreas-piloto, onde nada foi plantado.

O estudo comparativo dos sftios naturais e em reabilitação, periodicamente observados e analisados por diversas técnicas indicativas dos parâmetros texturais, estruturais, mineralógicos, geoquímicos e orgânicos, pode indicar a importância de cada um destes parâmetros no desenvolvimento e evolução das micro e macroestruturas do solo, responsáveis pela eficiência da interação solo-vegetação (formação das estruturas cicladoras). Este processo natural de desenvolvimento de estruturas pode acontecer mais rapidamente se os parâmetros responsáveis forem otimizados artificialmente.

Os resultados verificados até o momento mostraram que um conjunto de procedimentos fundamentais simultâneos pode desencadear uma rápida reabilitação do solo, com o desenvolvimento de microestruturas, aumento do teor de matéria orgânica e retenção de argila e umidade, dando condições para a instalação de espécies nativas pioneiras. Este conjunto de procedimentos inclui a preparação da topografia, a colocação do top soil original, o preparo agronômico com sulcagem, correção e adubação do solo, e o plantio de gramíneas, principalmente capim gordura, além das espécies nativas. Nas áreas onde faltou uma ou mais etapas deste conjunto, os resultados são insatisfatórios a péssimos, com prejuízo das características de fertilidade dos solos. 